\title{
Secretos y confesiones: lectura de pasiones lésbicas en la literatura argentina y en una obra particular, la narrativa de Silvina Ocampo
}

\author{
Secrets and confessions: reading of lesbian passions in Argentine \\ literature and in a particular work, Silvina Ocampo's narrative
}

Patricia Rotger

\begin{abstract}
Resumen
En el marco de una investigación que busca trazar los itinerarios de aparición de la identidad lesbiana en la literatura argentina, el trabajo traza un panorama general de los modos de representación del lesbianismo y se detiene en las estrategias que se evidencian en cuentos de Silvina Ocampo a la hora de narrar la emergencia del deseo lésbico.

Algunos cuentos de esta autora enmarcan las historias en los registros confesionales de la carta o el diario íntimo. Estos géneros menores son propicios para el juego de revelaciones de pasiones secretas que tienen como protagonistas a mujeres. Me propongo observar cómo la combinación de silencios y retaceos informativos conforman los secretos del clóset creando un efecto de invisibilidad de esta identidad.
\end{abstract}

Palabras claves: sexualidad - secreto - clóset - lesbianismo - invisibilidad.

\begin{abstract}
In the framework of a research that seeks to trace the routes of the appearance of the lesbian identity in Argentine literature this piece of work gives a general overview of the modes of representation of lesbianism and stops at the strategies that can be seen in Silvina Ocampo's stories at the time of narrating the emergence of the lesbian desire.

Some of the tales of this author frame the stories on the records of the confessional letter or diary. These minor genres are favourable for the game of revelations of secret passions that have women as protagonists.

My intention is to observe how the combination of silences and lack of information make up the secrets of the closet creating an effect of invisibility of this identity.
\end{abstract}

Key words: sexuality - secret - closet - lesbianism - invisibility.

Fecha de recepción: 17 de mayo de 2012

Fecha de aprobación: 15 de febrero de 2013

Profesora y Licenciada en Letras, Magister en Sociosemiótica y Dra. en Letras. Docente en la Escuela de Letras, Facultad de Filosofía y Humanidades de la Universidad Nacional de Córdoba, Argentina. Integrante del Programa de Género del Centro de Estudios Avanzados (UNC) y directora del proyecto de investigación "Multitudes sexuales: retóricas y ficciones de género y sexualidad en la literatura". patrih@arnet.com.ar 
El presente trabajo forma parte de un proyecto que busca trazar un itinerario de representaciones del deseo lésbico en la literatura argentina. Esta tarea nos conduce a ejercitar una lectura detenida en los juegos de sentidos implícitos que muestran los textos. Podemos conjeturar que el trabajo de lectura se redefine de una manera específica a la hora de querer señalar cómo aparecen estos "raros" afectos en el campo de las representaciones literarias porque, justamente, el deseo lésbico ha sido siempre silenciado en nuestra cultura y la literatura pone en evidencia ese silencio.

En efecto, muchas veces el deseo lésbico ha sido construido como secreto y ha sido confinado al silencio. Gabriel Giorgi afirma que el secreto construye:

"...escenarios, relatos, percepciones que van a otorgar a la homosexualidad su forma y sus condiciones de acceso a la representación. Hay allí una economía, un conjunto de reglas que hacen del secreto una estética-condiciones de percepción, reglas de representación-yuna política-construcción de escenarios, de identidades, de marcos colectivos de significación, etc." (Giorgi, 2000: 243).

De esta forma, continúa Giorgi,

"... alrededor de las representaciones de la homosexualidad hay un saber del secreto que se especifica en juegos retóricos singulares, de dificultosa fijación interpretativa, y cuyo régimen de lectura reclama siempre miradas dobles y movimientos constantes" (Giorgi, 2000: 243).

Por eso la lectura trabaja en ese espacio borrado por el texto que crea una zona de sentidos ambiguos e inciertos que no dan nombre a estas identidades pero sí crean espacios densos de significados implícitos que las rodean, como veremos en algunos cuentos de Silvina Ocampo.

Un deseo confinado al silencio por lo que tiene de revulsivo en tanto cuestiona los órdenes establecidos y es indiferente a la autoridad machista ${ }^{2}$. El lesbianismo no se reduce a una elección sexual sino a un estilo de vida que socava los cimientos de la heterosexualidad obligatoria ${ }^{3}$ y disloca los roles y estereotipos genéricos arraigados por la cultura falocéntrica. Este impulso subversivo ${ }^{4}$, que cuestiona los mecanismos de poder y las coerciones sociales extendidas hacia los modos de vida, ha sido siempre silenciado e invisibilizado por nuestra cultura. De manera que la literatura ha mostrado

2 Monique Wittig, referente del feminismo lesbiano de los años sesenta, en su citado trabajo La mente heterosexual y otros ensayos, plantea la conocida afirmación "las lesbianas no son mujeres", justamente porque las lesbianas se sitúan fuera del sistema de intercambio (hetero)sexual y, según Wittwig, "el signo mujer tiene significado solo en los sistemas de pensamiento heterosexuales y en los sistemas económicos heterosexuales. Las lesbianas no son mujeres". Así, las lesbianas están fuera del dominio de los hombres: "Lo que crea a una mujer es una relación social específica con un hombre, una relación que hemos llamado en otro lugar esclavitud, una relación que implica obligaciones personales y físicas además de obligaciones económicas... una relación a la que las lesbianas escapan rehusando ser o seguir siendo heterosexuales" (Wittig, 2006: 112-13).

3 Adrienne Rich, en Heterosexualidad obligatoria y existencia lesbiana, denomina heterosexualidad obligatoria "al complejo de fuerzas a través de las cuales las mujeres han sido convencidas de que el matrimonio y la orientación sexual hacia los hombres son inevitables, a pesar de ser componentes insatisfactorios u opresivos de sus vidas"(Rich, 1985: 15). Retratado e historizado en los libros La herejía lesbiana de Sheila Jeffreys y La amante celeste de Rosanna Fiocchetto. 
permanentemente estas tensiones sociales traducidas en formas más o menos indirectas, oblicuas y sutiles de contar los itinerarios, fábulas y circuitos deseantes de una identidad que siempre fue llamada a silencio. ¿Cómo representar entonces aquello que se oculta? ¿De qué manera se habla y se imagina la figura de la lesbiana en un mundo que constantemente la niega? ¿Cómo se piensa lo diferente? ¿Qué atributos se le conceden? En suma, lo que nos interesa indagar es la manera en que la literatura como máquina de percepción imagina a la lesbiana y cómo construye los sentidos que se aglutinan en su entorno ${ }^{5}$.

Inicialmente cuando se trata de observar las distintas representaciones de la lesbiana en la literatura argentina se puede pensar que es una tarea infructuosa y, a priori, aparece el vacío de una ausencia anunciada por el silencio continuo al que fue confinada 6 . Pero cuando la investigación avanza, advertimos cómo esta figura de improbable aparición en nuestra literatura va emergiendo en distintos momentos y autores, conformando toda una serie que de a poco va construyendo los distintos matices de sentido que toma esta identidad. Muchas veces no se la puede identificar con la claridad de un carácter identitario, sino más bien como un flujo deseante que señala afectos y pasiones entre mujeres o con las formas de lo que Adrienne Rich llamó "continuum lesbiano", es decir, un conjunto de experiencias, afectos y solidaridades compartidas por mujeres: "una gama de experiencias ginocéntricas" (Rich, 1985: 23).

De esta manera, y de cara a nuestra literatura contemporánea, podemos rastrear distintos momentos en los que la narrativa configura y modeliza la figura de la lesbiana: muestra sus pasiones, sus voces, su erotismo, sus secretos y también sus fábulas, es decir, las historias que protagonizan, marcando así los itinerarios narrativos imaginados para esta figura identitaria descentrada y marginal.

$5 \quad$ No hablamos de una literatura lesbiana, ni trabajamos sobre escritoras lesbianas, más bien, observamos, en un campo disperso de textos, su emergencia y recurrencia.

Respecto de las posibilidades de pensar en una literatura lesbiana se puede ver el artículo de Beatriz Suárez Briones (2008): "A Chloe le gustaba Olivia. Acerca de la identidad y la escritura lesbiana", en García Rayego y Sánchez Gómez, Que sus faldas son ciclones. Representación literaria contemporánea del lesbianismo en lengua inglesa. Barcelona: Egales. En este artículo la autora analiza tres criterios no excluyentes para definir la literatura lesbiana: la autoría (una escritura lesbiana es la que produce una escritora lesbiana), el tema y la recepción (un texto lesbiano es el que la lectora lesbiana decide leer como tal).

6 De hecho, la continua invisibilidad habilita la pregunta:¿existen las lesbianas? Es tal la invisibilidad que se cuestiona la propia existencia. Esta imposibilidad de ver a la lesbiana es paradigmática en el caso policial Dolores Vázquez-Wanninkhof que analiza Beatriz Gimeno en Gimeno, Beatriz (2008): La construcción de la lesbiana perversa. Barcelona: Gedisa. En este libro la autora demuestra de qué manera los medios de comunicación españoles silenciaron la relación lésbica de Vázquez (acusada del crimen de la niña Wanninkhof) y la madre de la víctima. Pero luego visibilizan la identidad lesbiana de Vázquez para construirla como única sospechosa y lo hacen mostrando un alto índice de lesbofobia: le atribuyen perversidad, frialdad y ausencia de emociones. El caso fue resonante en España y concluyó con la condena (basada en pruebas que después resultaron falsas) a quince años de prisión para Dolores Vázquez. La acusada cumplió diecisiete meses de prisión, se descubrió y condenó al verdadero asesino y el ministerio de justicia indemnizó a Vázquez por lo que consideró un "error". Mediante el análisis del caso, Beatriz Gimeno demuestra cómo la sociedad, la prensa y la justicia actuaron con enormes prejuicios lesbofóbicos al juzgar y culpabilizar a Dolores Vázquez que siempre declaró su inocencia. 
Sin dudas, a la hora de trazar un recorrido de aparición de la figura de la lesbiana hay que detenerse en el texto En breve cárcel de Silvia Molloy, novela emblemática de las relaciones lésbicas que fue publicada en 1982 y que marcó un claro momento de visibilidad lésbica en el campo de representaciones literarias. Hay un antes y un después a partir de su publicación en lo que respecta a la composición de mundos narrativos habitados por lesbianas. La novela de Molloy se presentaba, para ese entonces, como el primer espacio de irrupción de la sexualidad lesbiana en su plena exposición de modos afectivos femeninos y agudas sensibilidades puestas al descubierto: la lesbiana aparecía para mostrar su caudal afectivo y su complejo mundo de pasiones suspendidas. Lo que se representaba era su mundo íntimo, no tanto los recovecos de un secreto, nada de ese fatalismo tortuoso, sino más bien los pliegues de su percepción sensible, los tonos conmovidos y fatigados de un amor tan infructuoso como encendido. Como si fuera necesario humanizar a la lesbiana, como si esa fuera la posibilidad de su aparición, desnudarla hasta los huesos, mostrar su desgarro de amor y, finalmente, hacerla escribir: esa es su productividad, parir palabras para investirse de sentidos, escribir no para buscar sino para encontrarse, escribir no para liberar la imaginación ni para fantasear sino para ajustarse, para ceñirse a una verdad que despliega en todos sus matices y se expande a su percepción del mundo.

No volvemos a encontrar este retrato intimista de la lesbiana en ningún otro texto. Por eso esta novela es paradigmática, porque describió un tono irrepetible, que no aparece ni en El círculo imperfecto de Alicia Plante ni en Esto no es amor de Patricia Kolesnicov que son, quizás, las novelas posteriores con las que podría emparentarse. En ambas novelas se recrean los itinerarios pasionales de protagonistas lesbianas pero desde otro ángulo, donde las relaciones amorosas responden más a los códigos de las aventuras pasionales, recortadas sobre un dramatismo más itinerante y fútil, lejos de aquella subjetividad replegada en los cabildeos demorados de una espera de lo trascendente.

Es que han pasado más de veinte años entre la novela de Molloy y estas más contemporáneas y el sujeto amoroso ya no es el mismo: si la protagonista de En breve cárcel se construye desde un legado más humanista y romántico, los personajes de El círculo imperfecto y Esto no es amor encarnan un escepticismo ya no transformado en escritura de la espera, que como la protagonista de la novela de Molloy escribe para mitigar la distancia a la que la somete su amada, sino un escepticismo vital que se traduce en el trazado más de itinerarios que de intensidades, de pieles más que de carnes, de búsquedas incesantes más que de angustiosos encuentros.

Hay que pasar a los textos de Dalia Rosetti, Me encantaría que gustes de mí o Durazno Reverdeciente, para que la lesbiana se divierta un poco, para que pierda esa carga de intensidades y, finalmente, se encuentre con su estereotipo. Resulta paradójico que el encasillamiento la libere pero justamente, desde los bordes de una estética kitsch y popular emparentada con los códigos de la telenovela, la lesbiana se regocija en su propia intrascendencia, se libera de todos los mandatos y con una inocencia superflua se entrega a la aventura. 
Algo parecido ocurre en La prueba de César Aira, publicada en 1992, donde los anteriores condimentos también están presentes. Mao y Lenin, las protagonistas, son también dos aventureras adolescentes muy estereotipadas, pero, en este caso, las lesbianas encarnan una revolución, un acto de amor, creen en algo y luchan por ello, distintas de la despreocupada vitalidad de los personajes de Rosetti.

Para pensar a la lesbiana en coordenadas políticas hay que volver atrás en este breve panorama histórico que no se propone la exhaustividad como tarea sino, más bien, la construcción de una serie de lectura que dé cuenta de ciertos momentos de emergencia de la lesbiana en la literatura argentina, y recuperar una novela anterior a En breve cárcel. Se trata de Monte de venus, de Reina Roffé, publicado en 1976 que fue, ciertamente, la novela que abrió el juego de representaciones futuras de la lesbiana. En este caso el derrotero amoroso de la protagonista está signado por la marginalidad social y los sucesos políticos previos al golpe militar del 76. Esta novela, que mostró con sencilla naturalidad la sexualidad lesbiana asumida como modo de vida, fue censurada por la dictadura militar y retirada de las librerías. Seguramente por esta desaparición forzada, que la convirtió en una pieza difícil de hallar en las bibliotecas, su impacto cultural fue reducido solo al reconocimiento de pocos especialistas que la reconocen como pionera en el acto de representar esta identidad marginal.

Tal vez para observar con mayor claridad a la lesbiana, ya no aislada en su fuero íntimo y desentendida de lo social sino inmersa en su tiempo político, hay que detenerse en el conocido cuento de Rodolfo Fogwill, "La larga risa de todos estos años", publicado en 1983, donde no solo se pueden leer los juegos de violencia como mecanismos constitutivos de la relación amorosa, sino también como metáforas de la violencia política ejercida por los militares en la dictadura. Al mismo tiempo, los procedimientos de escritura dan cuenta de un trabajo de ocultamiento y revelación que busca generar cierta sorpresa en el lector al hacer evidente recién al final la verdadera identidad de la protagonista.

Estos ocultamientos y juegos de silencios también se pueden observar en un cuento de Silvina Ocampo, "Carta perdida en un cajón" publicado en 1959. De manera que entre ambos cuentos se puede trazar una línea de continuidad en lo que se refiere a la construcción de la sexualidad como secreto. Si el cuento de Fogwill se vale del secreto como un efecto narrativo que busca desestabilizar los recorridos de lectura previstos, el de Silvina Ocampo jamás revela el secreto, más bien lo trabaja desde su continua opacidad mostrando la densidad de las relaciones pasionales entre mujeres lejos de ninguna constatación identitaria.

Si retomamos la línea política de esta serie hay que mencionar dos novelas de Guillermo Saccomanno, La lengua del malón y 77 donde la lesbiana aparece claramente politizada. En el contexto del bombardeo a Plaza de Mayo en 1955 y la dictadura del último gobierno militar, respectivamente, aparecen las lesbianas en tensión con el peronismo o como guerrilleras de izquierda y, también, nuevamente la práctica de la escritura. Los personajes de ambas novelas escriben: una lo hará para dislocar la tradición 
literaria gauchesca y, la otra, para retratar el dilema que suscita la combinación de la homosexualidad con la militancia guerrillera.

A la presentación de esta serie se le podrían agregar otros textos. Pienso en, por ejemplo, La condesa sangrienta de Alejandra Pizarnik que aporta toda la pintura de un imaginario gótico para la figura de la lesbiana: la vida de Erzebeth Bathory, la condesa que busca rejuvenecer bañándose en la sangre de las doncellas que sacrifica para su provecho. El vampirismo y la perversidad de Erzebeth escenifican la mácula social que acompañó la figura de la lesbiana especialmente en el siglo XIX y parte del XX.

Según Beatriz Gimeno los distintos modelos de vampiras aparecen siempre como depredadoras sexuales. Afirma: "Esta imagen de la lesbiana como depredadora sexual será una de las más duraderas, omnipresentes y destructivas imágenes del estereotipo lesbiano en general hasta nuestros días" (Gimeno, 2008: 148).

En efecto, hay una idea de insaciabilidad sexual y de búsqueda de posesión y control que ejercería la invertida sobre otras mujeres que las hacía abandonar su posición natural en el orden heterosexual. Esta influencia, afirma Gimeno (2008), era vista como negativa respecto de las mujeres más jóvenes a las que se seducía con malas artes y se las conducía a la perdición.

Así como en el texto de Pizarnik se configura la imagen mítica de Bathory como lesbiana, asesina y vampírica, El affair Skeffington (1992) de María Moreno muestra la imagen liberal y desprejuiciada que conforma el universo del lesbian chic en la ParísLesbos de los años 20. El affair Skeffington es una mezcla de novela y biografía apócrifa donde María Moreno ficcionaliza la vida de Dolly Skeffington, una poetisa estadounidense llamada Olivia Streethorse que vive en París en los años 20 y participa de la vida de los salones intelectuales de la época. María Moreno retrata la París-Lesbos de los años 20 que reunió a mujeres de letras: escritoras, editoras, saloneras que tenían un estilo de vida desprejuiciado y libre ${ }^{7}$. Se trataba de mujeres artistas e intelectuales que conformaban un grupo alegre y despreocupado de la propia imagen. Como señala Gimeno:

"El círculo de lesbianas de la Rive gauche parisina funciona como un importante grupo de apoyo empeñado en crear una autoimagen positiva muy alejada de la imagen desgraciada y oscura, de enfermedad y dolor con la que la literatura presentaba a la lesbiana" (Gimeno, 2005: 162-163).

Ambos textos dan cuenta de las distintas modalidades de percepción que produjeron y construyeron la identidad lesbiana, oscilante entre estos polos de significaciones que

"París-Lesbos no se relevaba -dice Moreno-, existía por enriquecimiento, las nuevas generaciones podían toparse con las viejas: Anais Nin, Gertrude Stein, Alice Toklas, Natalie Barney, Djuna Barnes. Fue durante tres décadas que las habitantes de París-Lesbos continuaron abriendo salones, fundando editoras o librerías para ofrecerse como bacantes a las artes y a las letras". Moreno, María (2000). "El affair Skeffington" en Brizuela, Leopoldo (Comp.), Historia de un deseo, el erotismo homosexual en 28 relatos argentinos contemporáneos. Buenos Aires: Planeta. 
la muestran perversa y asesina, un extremo patologizado que contribuyó a excluirla y estigmatizarla. Y, el otro polo, más afín a forjar un estereotipo abierto a la aceptación social por su cuota de ambigüedad y su pose libertina ${ }^{8}$.

Como señala Baczko, "Los imaginarios sociales son referencias específicas en el vasto sistema simbólico que produce toda colectividad y a través de la cual ella se percibe, se divide y elabora sus finalidades"(1991: 28). De este modo los estereotipos que expresan la identidad lesbiana dan cuenta del imaginario social que distribuye roles y posiciones sociales, expresa e impone ciertas creencias comunes y designa identidades marcando los territorios y fronteras de esta.

De alguna manera los estereotipos que se construyen en torno a la identidad lesbiana también dan cuenta de los dispositivos de control que regulan y legitiman algunas representaciones sobre otras y han forjado históricamente los sentidos y las significaciones sociales, controvertidas, polémicas y revulsivas, que esta identidad condensa.

Ambos textos permiten observar los distintos estereotipos que representan la figura de la lesbiana y que aglutinan sentidos codificados culturalmente en direcciones opuestas: la imagen perversa de la asesina vampira o la imagen liberal y desprejuiciada de la bohemia parisina, dando forma así al universo imaginario que habita la lesbiana en la cultura.

A continuación me detendré en algunos textos de Silvina Ocampo para observar cómo aparecen construidos los roles de género y de qué maneras sutiles se representa el deseo lesbiano que nunca es enunciado como tal sino trabajado desde los contornos del secreto. A propósito, el libro Epistemología del armario de Eve Kosofsky Sedgwick plantea de qué manera "las relaciones del armario -las relaciones de lo conocido y lo desconocido, lo explícito y lo implícito en torno a la definición de homo/ heterosexualidad-pueden ser especialmente reveladoras acerca de los actos discursivos de modo más general" (Sedwick, 1996: 13). Para Sedgwick, el armario ha dado forma a la subjetividad homosexual y a la dinámica de sus relaciones en los siglos XIX y XX. A partir del empleo de la palabra homosexualidad situado en los últimos decenios del siglo XIX, cuando los discursos taxonómicos de la medicina, el derecho y la psiquiatría la nombran, la observan y la analizan, se resignifican también los usos del silencio y la modalidad del secreto aparece como forma de resguardo y protección a la mirada acusadora de la ciencia y la sociedad. De esta manera, la discreción, el silencio, los eufemismos y rodeos del lenguaje fueron instrumentos necesarios para esconder un deseo que no podía decir su nombre.

8 Dice Moreno: "El safismo era una voluptuosidad social que aún no promovía lazos de afiliadas. . las anandrines bebian curaco con hielo, comían lonjas de pescado crudo arrollados en varitas de marfily se escribian entre ellas libros horribles y encantadores, salpicados de baudelarismo sombrío, chinerías a lo Pierre loti y apotegmas de boulevard. Renée Vivien, la soberana, era una poetisa inglesa que con sus ojeras profundas, su cuerpo sin densidad y sus abismos de opereta parecía una precursora de los darks"(Moreno, 2000: 145) 
Por supuesto, la literatura pone en escena estos retaceos informativos y juegos de implícitos de manera ejemplar. Sedgwick (1996) los analiza en Proust para mostrar no solo el espectáculo del armario, sino también cómo se lo habita y cómo desde allí se construye un punto de vista.

\section{PASIONES AFECTIVAS EN LA NARRATIVA DE SILVINA OCAMPO}

Andrea Ostrov en El género al biés (2004) trabaja la ambigüedad en algunos cuentos de Silvina Ocampo resaltando especialmente el uso de la indeterminación genérica en un texto como "La Continuación" del libro La Furia (1959) en donde no hay marcas gramaticales que "permitan inferir el género del sujeto de la enunciación de este relato" (Ostrov, 2004: 40). Sin embargo, en esta carta el yo que escribe se ha leído como femenino y el tú al que se dirige como masculino, lo que señala que la crítica ha leído como heterosexual el vínculo entre los personajes. En efecto, aunque el texto no presenta marcas gramaticales que indiquen el género de los protagonistas, trabaja con ciertos estereotipos de género: el tono de reclamo y reproche de la carta, la inestabilidad emocional de la narradora, el uso del género epistolar, permiten hablar de un enunciador femenino mientras la posesión del dinero, el éxito profesional y la iniciativa tomada para dar un beso se aceptan como rasgos masculinos. De esta forma, señala Ostrov, el acto de lectura repone las marcas genérico-sexuales que no están en el texto y así muestra:

"... la imposibilidad de sostener la lectura en el terreno de la ambigüedad y de la indefinición genérica de los personajes... lo cual confirma la hipótesis de Judith Butler según la cual un cuerpo no generizado en función de la oposición hombre/mujerno resulta culturalmente inteligible" (Ostrov, 2004: 41).

De manera que allí donde el texto crea ambigüedad, la lectura apela a las convenciones genéricas para dotar de sentido a un relato que intenta sustraerse a los moldes prefijados y provocar cierto extrañamiento.

Hay otro cuento de Ocampo que también es una carta y que igualmente se inicia con el escamoteo de las marcas genéricas pero que hacia el centro del relato caracteriza como femeninas a ambas protagonistas. Es en este texto en el que intentamos leer las huellas de una pasión más explícita entre mujeres. Se trata de "Carta perdida en un cajón", otro relato de La Furia en el que en el marco de la escritura epistolar una enunciadora desbordada expresa sus sentimientos hacia su destinataria. A propósito del registro de esta carta Matilde Sánchez expresa "Quien lea 'Carta perdida en un cajón' se preguntará qué cosa es el sentimiento amoroso, cuando su contrario, el odio, requiere el mismo estilo" (Sánchez, 1991: 17) Justamente aquí el desprecio se manifiesta con un énfasis desmedido que se muestra como la otra cara de la pasión amorosa. Es el relato de un interrogatorio obsesivo que, si bien a veces adopta un estilo directo, no pierde su carácter retórico: aquella pregunta sin destino, como es siempre la pregunta del reclamo, sin respuesta, que no necesita una voz ajena a sí misma: "¿Cuánto tiempo hace que no pienso en otra cosa que en ti, imbécil, que te intercalas entre las líneas del libro que leo, dentro de la música que oigo, en el interior de los objetos que miro?"(Ocampo, 1991: 35). 
La carta evoca al otro, recuerda con una mezcla de placer y odio a su destinataria en todas sus formas, mostrando en ese detallismo un deleite sinuoso que se viste de desprecio:

"Pensar de la mañana a la nochey de la noche a la mañana en tus ojos, en tu pelo, en tu boca, en tu voz, en esa manera de caminar que tienen, me incapacita para cualquier trabajo. A veces al oir pronunciar tu nombre mi corazón deja de latir. Imagino las frases que dices, los lugares que frecuentas, los libros que te gustan. En medio de la noche, me despierto con sobresaltos preguntándome ¿dónde estará esta bestia?' o ¿con quién estará?'” (Ocampo, 1991: 35).

Más adelante se devela que la destinataria de esta carta es Alba Cristian, una compañera del colegio y el relato se detiene en narrar los sentimientos de celos que sufría la narradora ante la intromisión de otro personaje:

"... Maxima Parisi te enseñó unas tarjetas postales que no quiso enseñarme a míy que al final de la tarde, comiendo un helado de frambuesa, se recostó sobre tu hombro en el ómnibus que nos llevó de vuelta al colegio. En aquella intimidad que me excluía, sentí la amenaza de otras desventuras" (Ocampo, 1991: 36).

El relato narra desde la voz de la protagonista ese mundo de afectos exacerbados entre las amigas creando desde el tono obsesivo y confesional, que juega con los bordes desdibujados de los límites entre el desprecio y el amor, un relato íntimamente pasional y una voz cautivada por el objeto amado en todas sus formas:

"Ningún amante habrá pensado tanto en su amada como yo en ti. Recuerdo siempre tus manos levemente rojas, y la piel de tus brazos oscura en los pliegues del codo o en el cuello como arena húmeda ¿Será suciedad?, pienso, esperando con un defecto nuevo lograr la destrucción de tu ser tan despreciable" (Ocampo, 1991: 35).

Este escenario íntimo que la ficción construye en el marco subjetivo y privado de la correspondencia habilita el espacio de la confesión. En "Carta perdida en un cajón" se presenta la figura de un sujeto que habla sin pudor porque es en el enunciado íntimo donde el sujeto encuentra la posibilidad decible de su goce: la verdad. En efecto, la voz se torna confesión, requiere un ámbito íntimo y es, al decir de Foucault, "...una de las técnicas más altamente valoradas para producir lo verdadero" (Foucault, 1992: 74).

Lo indecible públicamente (el odio, el plan desechado del crimen) encuentra en el ámbito secreto de la confesión, y en el registro íntimo de la carta, su espacio de decibilidad. En la medida en que lo que se violenta en la confesión son las reglas de interacción social, su espacio no puede ser sino íntimo y por esta razón no hay culpa en el confeso ocampiano, porque con una carta no dirigida, con un otro que no es sino el yo, la figura del confesor es solo provocativa, pero no evaluadora.

Si bien la palabra se dirige a otro, la escritura epistolar es también una "escritura de sí" (Foucault, 1989) en tanto ese ejercicio de introspección es una vuelta sobre sí 
mismo. En este caso no aparece una interioridad dominada en su posesión (no hay un orden ni disciplina "burguesa" que intente asir "el adentro" y devorarlo), sino como espacio de visibilidad que ocupa y dirige la mirada de este confeso. Un régimen de percepción que en la imposibilidad de la alteridad construye una intimidad que se redobla como "alterada", como desconfiada en la apropiación y distanciada en el interior de ese desgobierno de mundo.

Al mismo tiempo, como señala Nora Bouvet en La escritura epistolar, "lo epistolar articula dos dimensiones: la ilusión de un acercamiento (una presencia) y la realidad de una separación (una ausencia)..." (Bouvet, 2006: 66). Así, en el texto de Ocampo se tematiza la presencia en el sentido de que el otro es convocado por medio de un relato repetitivo pero esta presencia narrativa no deja de exhibir una ausencia. En tanto es esta ausencia, como indica Bouvet, "el principio activo de la relación epistolar que impulsa sus estrategias enunciativas y condiciona las determinaciones estilísticas" (Bouvet, 2006: 68).

La carta crea un tiempo indeterminado hecho de presentes, el presente de quien escribe y el de quien lee, una temporalidad continua que en este caso está quebrada, ya que se trata de una carta que no llega a destino, una carta guardada. Sin embargo la lectura repone ese presente, actualiza esa voz escondida porque el pacto de ficción le cede al lector el lugar que tendría que haber ocupado la verdadera destinataria.

Este cuento propone al lector un espacio de intrusión en este diálogo pasional, casi como si se le concediese ser parte de un secreto, ese secreto que ni la propia involucrada y destinataria sabe. De manera que la lectura actualiza ese secreto escondido en un cajón que muestra la posición ambigua del enunciador respecto de lo que revela. Por un lado, el secreto es inherente a la enunciación epistolar en tanto determina específicamente su destinatario; por el otro, al ser fijado por escrito, el secreto se abre a la lectura, se objetiva, se muestra. Pero aquí la carta no llega a destino por lo que el secreto se mantiene para el destinatario pero no para los lectores del cuento que ocupan el lugar de la indiscreción. En efecto, el lector de este cuento ocupa el espacio de quien se entromete en la correspondencia ajena porque la comunicación se ha desviado, no ha llegado a destino.

Una carta que no se envía contradice su espíritu de comunicación y si esa carta está perdida en un cajón alude a un desinterés en su envío, una despreocupación. Sin embargo, ha sido guardada, no se ha destruido: refiere a un valor, pero a un valor postergado, relegado, dejado en segundo plano. Así se representa en Ocampo este itinerario de afectos desmedidos, intensos, significativos, decisivos a la hora de dejar huellas casi indelebles pero relegados, olvidados y silenciados.

Verdades reversibles: la paradoja en los enunciados íntimos ocampianos

"Para engañarme me decías siempre la verdad; para decirte la verdad yo siempre te mentía" (Ocampo, 1991: 189). 
En "Carta perdida en un cajón", la construcción del otro por el recuerdo incesante, mediante el juego de las figuras obsesivas que invaden la lengua del enunciado íntimo, lejos de darle a este un estatuto definido (enunciado de odio, de amor, de verdad, etc.) lo convalida en tanto se declara, con su exabrupto, la contrapartida. El enunciadoconfesión bordea la desmesura, la verdad que se enuncia resulta pretensión de verdad y la palabra de la narradora no resulta confiable: ¿es amor u odio lo que expresa?

Este enunciado íntimo parece decir dos verdades y estas son contradictorias. Desprovista de cordura, la narración genera una ambigüedad que socava la esencia misma de la confesión: su estatuto verídico. Finalmente, no queda claro si esta confesión muestra o enmascara.

El discurso de la confesión está llevado al paroxismo porque se confiesa todo, no hay reparos, porque no existe exterioridad legal o religiosa alguna que la incite o evalúe, porque la única autoridad y límite es el "sí mismo", le resta al enunciado su estatuto verídico y lo inviste de una nueva propiedad: su condición de reversible? Dicha propiedad está sustentada en tanto se alteran, hacia el final del cuento, los roles pretendidos por el enunciador: el destinador de odio deviene destinador de felicidad; el destinador de muerte deviene suicida:

"Quiero que sepas que debes tu felicidad al ser que más te desdeña y aborrece en el mundo. Una vez que ese ser que te adorna con su envidia y te embellece con su odio desaparezca, tu dicha concluirá con mi vida y la terminación de esta carta. Entonces te internarás en un jardín semejante al del colegio que era nuestra prisión, un jardín engañoso, cuidado por dos estatuas, que tienen dos globos de luz en las manos, para alumbrar tu soledad inextinguible" (Ocampo, 1991: 38).

En el enunciado íntimo, entonces, el estatuto de verdad lo da la pertenencia, es decir, la relación de propiedad del confeso con su palabra. Es una confesión en la que no importa tanto lo que se dice (porque no admite una exterioridad con la cual confrontar), sino lo que se tiene para decir: esta verdad me pertenece, parece decir el confeso ocampiano y lejos de buscar su prueba, busca su sentido.

Ahora, ¿qué clase de dominio ejerce este desvariado -en tanto reversible- sobre su palabra? Un dominio alterado o lo que es mejor, un falso dominio: el confeso juega en una tensión de fuerzas con su objeto " el sí mismo"y simula un gobierno de sí que se revela ausente.

Hablamos de reversibilidad en tanto se trata de un sentido que tiene la propiedad de girar sobre sí mismo para mostrar su contrario. Su figura es la paradoja ya que el sentido no es determinable, único, direccional: el sentido es doble ${ }^{10}$.

9 ".. la ambivalencia de los sentimientos permite una especie de reversibilidad entre la agresión y la culpabilidad..." Fuentes, Pablo (1988): "El relato paranoico", en Revista Crisis No 59, abril, p. 39.

10 "El buen sentido es la afirmación de que, en todas las cosas, hay un sentido determinable; pero la paradoja es la afirmación de los dos sentidos a la vez". Deleuze, Gilles (1989): Lógica del sentido. Buenos Aires: Paidós, p. 25. 
La carta-confesión es un lugar de enunciación, una modalidad específica de articulación del saber y del decir, que supone una palabra de verdad en tanto su circulación es restringida y secreta. La verdad es interior en tanto el poder designativo de la palabra recae sobre sí y está regida por la autoridad del sí mismo: su efectividad no depende sino de un orden narrativo que establece prioridades y distribuye sentidos a su subjetividad. Es una verdad ambigua, muchas veces contradictoria y que, por lo que tiene de reversible, se torna falsa" ${ }^{11}$. Puesto en evidencia, el confeso ocampiano, nunca renuncia a su máscara: "Quiero mi soledad, la quiero con mil caras impersonales" (Ocampo, 1991: 38).

Si el registro singular que una voz puede tomar para sí: aquel tono sobre el que gusta asentarse, definirse, diferenciarse y sobre el que esa voz despliega sus derechos de pertenencia y sus dominios de posesión. Si, en definitiva, esa voz es la del confeso y si ese "tono" que la distingue no es sino aquel que se regodea al hacer del "sí mismo" su objeto de discurso. Entonces, podemos hablar de una lengua íntima en la narrativa ocampiana en tanto hemos descrito un gesto de apropiación de una escritura íntima, de una voz que marca sus límites y centro: el yo ${ }^{12}$.

Pero ¿cuál es esa modalidad diferencial, específica y estratégica de la voz que instaura el enunciado íntimo? Es la palabra vulnerada, decimos. Esa palabra que secuestra para sí el valor de una voz que se quiere transparente en tanto no puede establecer un orden de reservas.

La palabra vulnerada es la palabra sin protección, el yo puesto en evidencia. El exceso, la verborragia del confeso (todo lo puede decir: el odio, el amor, el plan de un crimen, el engaño, el miedo, etc.) es propia de una voz que, desplegada en un espacio íntimo de decibilidad, no atenta contra una normativa social. El confeso ocampiano no tiene nada que ocultar, más que asegurar una verdad, atenta contra su univocidad.

Su único valor para intercambiar es su voz íntima: su secreto. Por eso, para el confeso ocampiano, pierde importancia su verdad revelada frente al placer que le provoca el saber que es el único capaz de pronunciarla. Más que una verdad, el confeso tiene un secreto guardado en un cajón y el lector es quien lo conoce; el confeso descubre, se (des)cubre para los otros (en la medida en que pretende una adhesión pasional cómplice), pero especialmente para sí.

Pero la palabra vulnerada es también una máscara, una estrategia, porque también esta palabra es vulnerante: se debate entre un reconocimiento y la agresión, pretende intimidar. Es íntima e intimidatoria.

11 Recordemos que es bajo el sentido de verdad reversible que debe entenderse el término "propietario". El confeso no es aquí un "dueño de sí", sino un distanciado (en tanto establece un régimen de percepción) de una intimidad que resulta desgobernada.

12 Dice Pezzoni: "... en esta compleja trama de los entre sí, lo buscado es el conocimiento de sí. Los relatos, los poemas de Silvina Ocampo avanzan impulsados por el empeño de situar, sitiar, poseer el propio Yo" (Pezzoni, 1984: 13). 
Esa carta guardada, esa palabra que no llega a destino, parecen crear una suerte de clóset que torna invisible esta identidad narrativa. La intensidad amorosa es revelada solo al lector bajo la forma de un deseo frustrado y una política de las relaciones afectivas extrema y desbordada que, finalmente, solo muestran una palabra vulnerada.

Otro texto, muy posterior al mencionado, "Teodora", escrito presumiblemente a finales de los años ochenta y que integra el volumen Las Repeticiones y otros relatos inéditos (Ocampo, 2006) aborda también la relación entre mujeres, pero desde un registro muy diferente donde nada parece lo que es y las identidades sexuales son muy ambiguas:

"En aquel tiempo ninguna mujer se vestía de hombre. Era triste sentir esa congoja, pagar de ese modo por su vida licenciosa y desbordante, que tanto había llamado la atención del mundo que la rodeaba. Vestirse de hombre era un acto heroico en esos tiempos. ¿De dónde sacaría fuerzas para seguir vestida como lo estaba, sin revelar a nadie su sexo?" (Ocampo, 2006: 120).

La protagonista, que siempre se vestía de varón, conoce a Tióbula que está embarazada y ambas son objetos de la malicia del pueblo: "En el pueblo, cuando Tióbula tuvo el hijo, se habló maliciosamente, en secreto, culpando a Teodora, quien se sintió agredida cuando supo que la acusaban de haber violado a Tióbula" (Ocampo, 2006: 122).

El juego de ambigüedades crece cuando se narran las dudas de Teodora: "¿Quién sería el padre? Se lo preguntó varias veces a Tióbula, que contestaba sin precisión. Teodora pensó que el padre estaría disfrazado de mujer y con mil artimañas la habría seducido" (Ocampo, 2006: 122).

De alguna manera lo que el relato pone en escena no es tanto la ambigüedad como la cualidad intercambiable de la identidad sexual: la mujer se viste de varón y es acusada de violar y embarazar a otra; el padre supuesto se ha vestido de mujer para seducir con artimañas. Así, la vestimenta construye el género en sus estereotipos más radicales: el hombre agresivo y la mujer histérica.

Algo similar ocurre en otros textos de Ocampo. Andrea Ostrov lo señala en "Las vestiduras peligrosas" en donde las vestiduras determinan la categorización de la protagonista como hombre o mujer y en "El sombrero metamórfico" en donde también "un sombrero tiene la virtud de transformar a los hombres y mujeres que lo llevan en su cabeza en mujeres y hombres, respectivamente. Por consiguiente, el género sexual aparece aquí como efecto del género textil" (Ostrov, 2004: 34).

Si bien Ocampo parece utilizar las vestiduras como una encarnación de ciertos moldes prefijados para el género, una obediencia a las normas convencionales, pero una obediencia desarticulada en tanto el personaje de Teodora se construye desde ciertas torsiones a estos estereotipos: si bien "cuidó al niño, como si fuera el padre" también "Adoptó al niño, le tejió la ropa, los pañales... y un precioso muñeco vestido de azul, con olas dibujadas, que lo hacían dormir de noche con rapidez vertiginosa" (Ocampo, 2006: 122). 
A menudo la crítica ha leído esta articulación entre obediencia y desvío de la norma en la narrativa de Ocampo, justamente es este desvío el que habilita nuestra lectura porque las convenciones de género son llevadas al extremo para mostrar su carácter de construcción cultural y así desnaturalizarlas.

Finalmente, en "Teodora", la pareja llama al niño con el nombre de Asombro marcando la indeterminación genérica de quien llaman "niño" en masculino pero que en verano usa "un vestidito de tul".

Otra vez Ocampo trabaja con el desajuste genérico y crea esa zona de indeterminación que evita una lectura reguladora que trate de dar inteligibilidad genérica estable a los cuerpos. Y lo hace por medio de un humor que parece burlarse de una lectura encasilladora porque, justamente, asombro, perplejidad y desconcierto es lo que puede provocar este mundo "raro" cuando el horizonte de lectura busca sentidos fijos y estables, muy lejos de la extrañeza, siempre inquietante y provocadora en sus falsas certezas, que habitan los personajes ocampianos.

\section{BIBLIOGRAFÍA}

Baczko, B (1991): Los imaginarios sociales. Buenos aires: Nueva Visión.

Bouvet, Nora (2006): La escritura epistolar. Buenos Aires: Eudeba.

Butler, Judith (2001): El género en disputa. El feminismo y la subversión de la identidad. México: Paidós.

Deleuze, Gilles (1989): Lógica del sentido. Barcelona: Paidós.

Fiocchetto, Rosanna (1993): La amante celeste. Madrid: Horas.

Fogwill, Rodolfo (1983): "La larga risa de todos estos años", en Ejércitos imaginarios, Buenos Aires: Centro Editor de América Latina.

Foucault, Michel (1992): Historia de la sexualidad I. La voluntad de saber. México: Siglo Veintiuno.

Foucault, Michel (1989): "La escritura de sí", en Abraham, Tomás, Los senderos de Foucault. Buenos Aires: Nueva Visión.

Fuentes, Pablo (1988): "El relato paranoico”, en Revista Crisis, número 59, abril, pp. 37-39.

Gimeno, Beatriz (2005): Historia y análisis político del lesbianismo. Barcelona: Gedisa.

Gimeno, Beatriz (2008): La construcción de la lesbiana perversa. Barcelona: Gedisa. 
Giorgi, Gabriel (2000): "Mirar al monstruo: homosexualidad y nación en los sesenta argentinos", en Daniel Balderston (editor), Sexualidad y Nación. Pittsburgh: Instituto Internacional de Literatura Iberoamericana.

Jeffreys, Sheila (1996): La herejía lesbiana. Madrid: Cátedra.

Kolesnicov, Patricia (2009): No es amor. Buenos aires: Suma de Letras.

Molloy, Syilvia (1982): En breve cárcel. Buenos Aires: Sigmur.

Moreno, María (2000): "El affair Skeffington”, en Brizuela, Leopoldo (Comp.), Historia de un deseo, el erotismo homosexual en 28 relatos argentinos contemporáneos. Buenos Aires: Planeta.

Ocampo, Silvina (1991): Las reglas del secreto. Buenos Aires: Fondo de Cultura Económica.

Ocampo, Silvina (2006): Las repeticiones y otros relatos inéditos. Buenos Aires: Sudamericana.

Ostrov, Andrea (2004): El género al biés. Cuerpo, género y escritura en cinco narradoras latinoamericanas, Córdoba: Alción Editora.

Pezzoni, Enrique (1984): "Estudio Preliminar", en Páginas de Silvina Ocampo, Buenos Aires: Celtia.

Pizarnik, Alejandra (2005): "La condesa sangrienta", en Pizarnik, A., Prosa completa. Buenos Aires: Lumen.

Plante, Alicia (2004): El círculo imperfecto. Buenos Aires: Sudamericana.

Rich, Adrienne (1986): "Heterosexualidad obligatoria y existencia lesbiana", en Sangre, pan y poesía. Barcelona: Icaria.

Roffé, Reina (1976): Monte de venus. Buenos Aires: Corregidor.

Rosetti, Dalia (2006): Me encantaría que gustes de mí, Buenos Aires: Mansalva.

Sánchez, Matilde (1991): "Prólogo" a Las reglas del secreto. Buenos aires: Fondo de Cultura Económica.

Saccomanno, Guillermo (2003): La lengua del malón. Buenos Aires: Planeta.

Saccomanno, Guillermo (2008)77. Buenos Aires: Planeta.

Sedgwick, Eve Kosofsky(1996): Epistemología del armario. Madrid: Ediciones de la Tempestad. 
Suárez Briones, Beatriz (2008): "A Chloe le gustaba Olivia. Acerca de la identidad y la escritura lesbiana", en García Rayego y Sánchez Gómez, Que sus faldas son ciclones. Representación literaria contemporánea del lesbianismo en lengua inglesa. Barcelona: Egales.

Wittig, Monique (2006): El pensamiento heterosexual y otros ensayos. Madrid: Egales. 